\title{
PANORAMA BRASILEIRO E ESPANHOL SOBRE TESES DE DOUTORADO NA ÁREA DAS ALTAS HABILIDADES/SUPERDOTAÇÃO
}

\author{
Ketilin Mayra PEDRO ${ }^{1}$ \\ Miguel Claudio Moriel CHACON ${ }^{2}$
}

RESUMO: No Brasil a área das Altas Habilidades/Superdotação (AH/SD) foi contemplada inicialmente na LDB 5692/71 (BRASIL, 1971), enquanto na Espanha o marco inicial se dá a partir do Real Decreto 696/1995 (ESPANHA, 1995), garantindo a esse alunado ao direito a identificação e atendimento. Visando contribuir com as pesquisas desta área, elaboramos o atual panorama brasileiro e espanhol em relação as teses de doutorado sobre AH/SD. Para a realização desta investigação consultamos a Biblioteca Digital Brasileira de Teses e Dissertações e a Base de datos de Tesis Doctorales. Foram localizadas um total de 70 teses, sendo 20 brasileiras e 50 espanholas. Com base na análise do título, do resumo e das palavras-chaves, elencamos categorias temáticas, sendo que foram predominantes: Identidade, Identificação e Avaliação. A primeira tese brasileira defendida data de 1989, enquanto que na Espanha a primeira tese é de 1990. Em relação ao local de publicação, no Brasil percebemos que há uma predominância em relação as universidades federais, enquanto na Espanha, a Universidade Complutense de Madrid destaca-se em número de publicações. Percebemos que embora o número de publicações tenha aumentado progressivamente, esse ainda figura-se como incipiente frente ao número de publicações de outras áreas e a demanda de trabalho que esses estudantes requerem.

PALAVRAS-CHAVE: Altas Habilidades/Superdotação. Revisão bibliográfica. Brasil. Espanha.

\section{INTRODUÇÃ̃O}

No Brasil a área das Altas Habilidades/Superdotação (AH/SD) foi contemplada pela primeira vez em documentos oficiais em 1971 através da LDB 5692/71 (BRASIL, 1971), tornando obrigatório o atendimento a esse alunado.

Após essa regulamentação outras legislações e políticas foram implementadas com o objetivo de assegurar a possibilidade de aceleração escolar, mediante a comprovação do aprendizado (BRASIL, 1996), definir quem são os estudantes AH/SD

\footnotetext{
${ }^{1}$ Mestre em Educação. UNESP - Universidade Estadual Paulista Júlio de Mesquita Filho, Campus Marília. Doutoranda em Educação. UNESP - Universidade Estadual Paulista Júlio de Mesquita Filho, Campus Marília. Marília - SP - Brasil. 17525-900 - ketilinp@yahoo.com.br.

2 Psicólogo. Pós-Doutor em Educação. Professor Assistente Doutor do Departamento de Educação Especial. UNESP - Universidade Estadual Paulista Júlio de Mesquita Filho, Campus Marília. Marília SP - Brasil. 17525-900 - miguelchacon@marilia.unesp.br.
} 
e garantir o direito ao enriquecimento por meio do atendimento educacional especializado (BRASIL, 2008).

A Política Nacional de Educação Especial na Perspectiva da Educação Inclusiva (BRASIL, 2008) define estudantes com AH/SD como aqueles que:

[...] demonstram potencial elevado em qualquer uma das seguintes áreas, isoladas ou combinadas: intelectual, acadêmica, liderança, psicomotricidade e artes. Também apresentam elevada criatividade, grande envolvimento na aprendizagem e realização de tarefas em áreas de seu interesse. (BRASIL, 2008, p.15).

Embora a atenção para esse alunado esteja contemplada nas políticas públicas educacionais brasileiras, sabemos que os estudantes com AH/SD ainda encontram-se invisíveis dentro do ambiento escolar, uma vez que, estes sequer são identificados, visto que o olhar da instituição escolar, está voltado muito mais para os estudantes que estão aquém do desenvolvimento considerado padrão, do que aqueles que encontram-se acima da média e apresentam altos níveis de criatividade e envolvimento com a tarefa (SMITH, 2008; ALONSO; BENITO, 1996).

$\mathrm{Na}$ Espanha os estudantes com AH/SD passaram a ser contemplados na política pública educacional a partir do Real Decreto 696/1995 (ESPANHA, 1995), o referido documento reconhece a atenção para estes estudantes, fazendo referência sobre a avaliação e o atendimento. Sendo que no ano de 2003 o Real Decreto 943/2003 (ESPANHA, 2003) regulas as condições para flexibilizar a duração dos níveis de ensino para os estudantes com AH/SD.

Além destes decretos, a Lei Orgânica de Educação (ESPANHA, 2006), aponta que os estudantes com superdotação intelectual precisam de uma atenção educativa especial, bem como os estudantes que apresentam deficiência, o objetivo de prover essa atenção específica a cada alunado é garantir a equidade de diferentes grupos de estudantes.

Por fim, a Lei Orgânica de Educação (ESPANHA, 2013), descreve que compete as administrações educativas adotar as medidas cabíveis para identificar e desenvolver precocemente as habilidades dos estudantes com $\mathrm{AH} / \mathrm{SD}$, a lei prevê também que as necessidades educativas desses estudantes podem ser atendidas por meio de planos de atuação individual ou programas de enriquecimento curricular.

Cabe salientar, que a Espanha tem uma estrutura organizacional distinta do Brasil, sendo que esta possui 17 comunidades autônomas (Andalucía, Aragón, Asturias, 
Ilhas Baleadres, Ilhas Canarias, Cantabria, Castilla - La Mancha, Castilla y León, Catalunya, Extremadura, Galicia, La Rioja, Madrid, Murcia, Navarra, País Vasco e Valencia) e cada uma dessas comunidades possuem regulamentações distintas para a educação. Sendo assim, a lei estatal não define quem é o estudante com AH/SD, cabendo a cada comunidade autônoma definir quem é esse alunado.

Tal falta de uniformidade em relação a conceituação de quem é esse alunado, causa alguns conflitos, sendo que um estudante pode ser considerado AH/SD em uma comunidade autônoma e em outra não (SANZ, 2015).

Em ambos os países percebemos que a área da AH/SD carece de uma uniformidade e que ainda há muitos aspectos que precisam ser discutidos e pesquisados, dessa maneira, faz-se necessário conhecer as produções acadêmicas da área, a fim de enriquecer a formação do pesquisador e evitar realizações de pesquisas alienadas que pouco contribuem para o avanço científico da área (SILVA, 1998). Segundo Omote (2014, p.21):

[...] há hoje um farto volume de publicações em periódicos e anais de eventos tratando de uma ampla diversidade de problemas que vêm a propósito na compreensão e equacionamento de questões implicadas na Educação Inclusiva e de seus correlatos. Para um avanço qualitativo expressivo pode estar faltando uma ampla revisão e sistematização dos resultados encontrados, e principalmente um vigoroso esforço para uma análise crítica e incorporação desses achados no corpo de conhecimentos já existente para a construção de referenciais teóricos sólidos [...].

Dessa maneira, o objetivo do presente estudo foi realizar um levantamento bibliográfico a fim de identificar: as temáticas, o ano e local de publicação de teses de doutorado do Brasil e da Espanha sobre a área das AH/SD, elaborando assim o atual panorama brasileiro e espanhol em relação as teses de doutorado que versam sobre esta temática.

\section{Método}

O levantamento bibliográfico brasileiro foi realizado na Biblioteca Brasileira de Teses e Dissertações (BDTD), esse portal tem por objetivo integrar em um único site informações de teses e dissertações existentes no país. 
Os descritores utilizados foram Altas Habilidades, Superdotação, Talento e Dotação, sendo que esses deveriam estar presentes no título, resumo ou palavras-chave das produções.

Em relação à variedade de descritores utilizados no levantamento bibliográfico, ressaltamos que no Brasil não há um consenso em relação à terminologia utilizada na área, sendo que a mesma sofre alterações de acordo com o referencial teórico utilizado, dessa maneira, optamos por utilizar todas as terminologias vigentes atualmente.

O levantamento bibliográfico espanhol foi realizado na Base de datos de Tesis Doctorales (TESEO) esse portal tem por objetivo integrar informações de teses de doutorado de universidades espanholas.

Para realizarmos a busca no TESEO estabelecemos os seguintes descritores: Superdotación; Altas Capacidades; Dotación e Talento, por serem essas as nomenclaturas utilizadas na Espanha para identificar estudantes com AH/SD.

Em ambos os levantamentos realizados algumas produções foram encontradas em mais de um descritor, sendo assim, após o término do levantamento foi necessário realizar uma verificação para descartar as produções repetidas.

\section{Resultados e discussões}

Por meio do levantamento bibliográfico realizado encontramos um total de 70 teses de doutorado sobre a temática, sendo 20 referentes ao Brasil e 50 à Espanha. A análise dos dados permitiu categorizar as temáticas das teses, identificar o número de produções por ano e a distribuição entre as universidades brasileiras e espanholas.

Para identificação da temática das produções analisamos o título, o resumo e as palavras-chaves. Diante disso, elencamos 7 categorias temáticas para as teses brasileiras: Atendimento, Contexto Social, Formação Docente, Habilidades Sociais, Identidade, Identificação e Levantamento; e elencamos 13 categorias temáticas para as teses espanholas: Atendimento, Avaliação, Características Socioemocionais, Criatividade, Família, Formação Docente, Gênero, Inclusão, Identidade, Identificação, Inteligência, Memória e Tecnologias da Informação e Comunicação (TIC).

As Figuras 1 e 2 apresentam respectivamente, as temáticas encontradas nas teses brasileiras e espanholas. 
Figura 1- Categorias temáticas das teses brasileiras

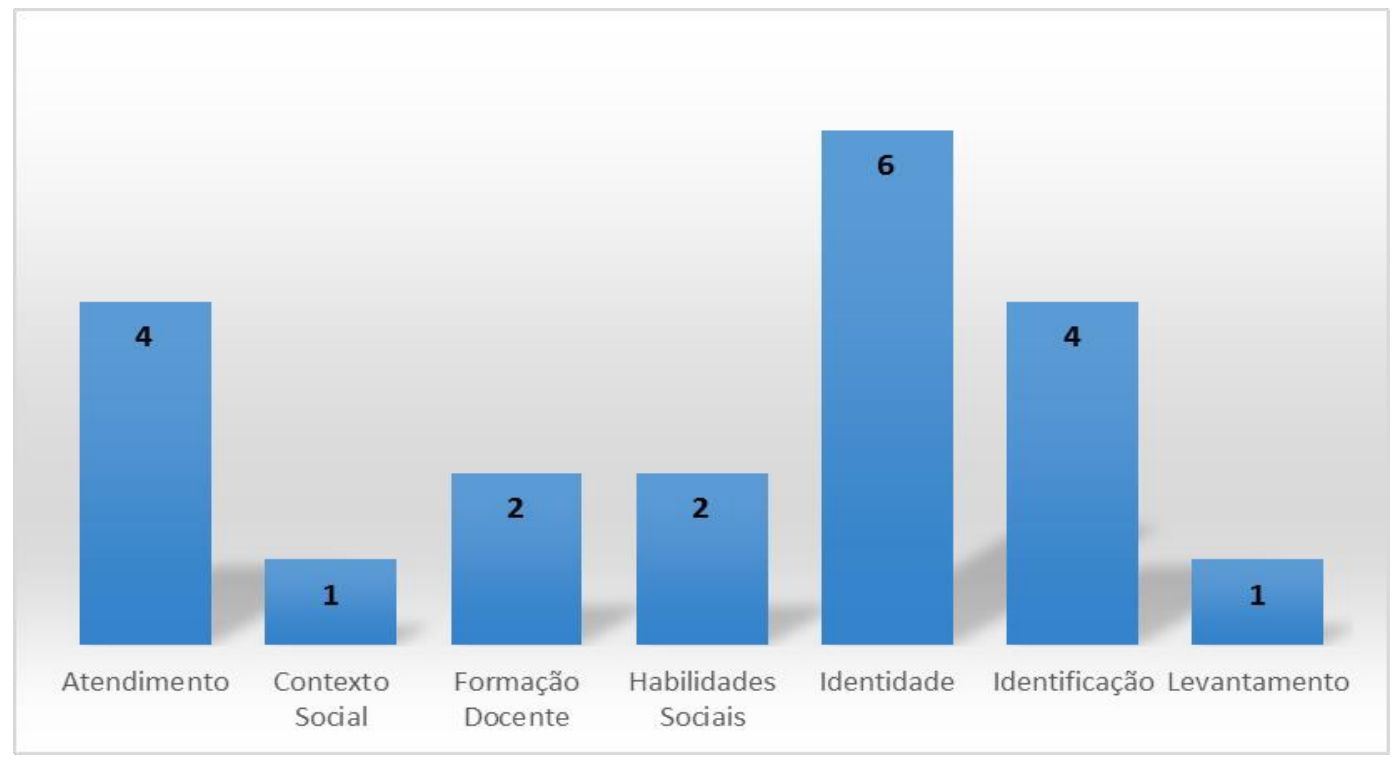

Fonte: Elaboração própria.

Figura 2- Categorias temáticas das teses espanholas

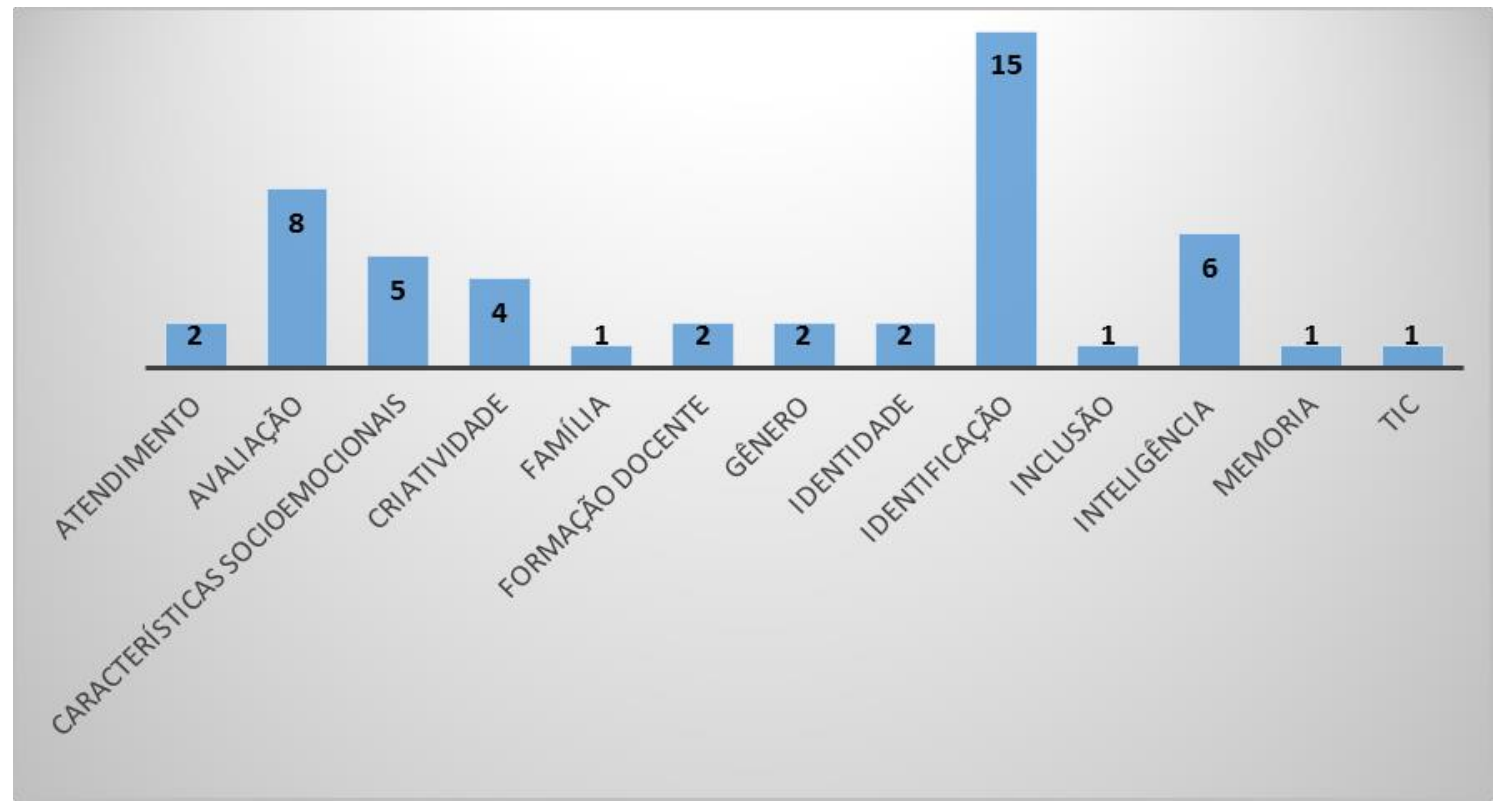

Fonte: Elaboração própria.

As temáticas que abarcam o maior número de publicações são Identidade e Identificação, e aquelas que são encontradas em ambos levantamentos são: Atendimento, Formação Docente, e novamente Identidade e Identificação.

$\mathrm{Na}$ categoria Identificação foram alocadas 19 teses, sendo 15 espanholas e quatro brasileiras, de acordo com a literatura é possível perceber que a identificação é um dos grandes entraves em relação aos estudantes com AH/SD (GARCÍA-RON; 
VÁZQUEZ, 2001; CHACON; PEDRO; KOGA, 2014), seja pela falta de uma definição de quem é esse alunado, ou de quais instrumentos devem ser utilizados no processo de identificação, visto que, alguns autores defendem a utilização de avaliações psicológicas enquanto umas das etapas de identificação (CHACON; PEDRO; KOGA, 2014; ALONSO; BENITO, 1996) e outros que realizam a triagem baseados em escalas de características que devem ser preenchidas por professores, pais, amigos e o próprio estudante (FREITAS; PEREZ, 2012).

Em relação ao número de estudantes identificados, os dados de pesquisa de Freitas (2014), revelam que no Brasil apenas 11.025 estudantes (0,44\%) encontram-se oficialmente identificados, enquanto que na Espanha (2014) o "Informe 2014 sobre el Estado del Sistema Educativo" aponta que o número de identificados está em torno de 12.490 (aproximadamente $0.15 \%$ ). Ao relacionar esses dados numéricos com a estimativa de Renzulli (1978), observamos o quanto o número de identificados é incipiente em ambos os países, visto que o autor afirma que de 10 a $15 \%$ da população em idade escolar apresenta AH/SD.

Sendo assim, a porcentagem de estudantes identificados é mínima tornando os estudantes com AH/SD completamente invisíveis no contexto escolar e tornando essa temática um importante objeto para investigação.

Categorizamos oito teses, seis brasileiras e quatro espanholas, na categoria Identidade, tais produções versavam sobre a percepção que o estudante com AH/SD tem sobre si mesmo, e também como seu entorno o percebe.

Paludo, Loos-Sant'Ana e Sant'Ana-Loss (2013, p.2) apontam que:

[...] o sujeito com capacidade acima da média, quando comparado em sua faixa etária -, como uma identidade diferenciada, também é constituída na inter-relação dos fatores biológicos, psicológicos e sociais. Assume-se, ainda, que a condição de ser superdotado tem influência em seu processo de desenvolvimento e no estabelecimento de relações com o mundo.

Acreditamos que a temática da identidade é relevante, visto que a maneira como o estudante com AH/SD se percebe e é percebido, irá influenciar no seu desenvolvimento acadêmico e nas relações pessoais, sendo que a percepção negativa pode levar este estudante a canalizar o seu potencial em atitudes e ações que não sejam saudáveis e nem aceitas moralmente, visto que o desenvolvimento moral é um aspecto importante que também deve ser trabalhado com este alunado. 
$\mathrm{Na}$ categoria Atendimento foram alocadas seis teses, quatro brasileiras e duas espanholas. No Brasil, existem várias iniciativas de caráter institucional e filantrópico que promovem identificação e atendimento aos estudantes com AH/SD como, por exemplo: o Programa de Atenção a Alunos Precoces com Comportamento de Superdotação (PAPCS) vinculado a Faculdade de Filosofia e Ciências UNESP/Marília (São Paulo), o Programa de Incentivo ao Talento (PIT) da Universidade Federal de Santa Maria (Rio Grande do Sul), o Centro para Desenvolvimento do Potencial e Talento (CEDET/ Minas Gerais) que conta com a parceria de pais de estudantes com AH/SD, entre outros. Além desses programas/centros, o governo federal criou em 2005 os Núcleos de Atividades de Altas Habilidades (NAAH/S), que em parceira com as Secretarias Estaduais de Educação devem prover o atendimento a estudantes com AH/SD. Embora haja algumas iniciativas para o atendimento desse alunado, sabemos que o número de projetos e/ou centros é incipiente, cabe salientar que a política pública brasileira prevê que além do atendimento extracurricular, esses estudantes podem ter suas necessidades educacionais atendidas por meio do enriquecimento curricular e também da aceleração.

$\mathrm{Na}$ Espanha existem diversas iniciativas privadas e de organizações não governamentais para o atendimento aos estudantes AH/SD: Centro Huerta del Rey coordenadora pela professora Yolanda Benito (Vallodoid), Centro Kleper (Barcelona), Associação de Altas Capacidades (Almería), Fundação Promete coordenada por Luis Cacho (La Rioja), Programa de Enriquecimento Educativo para Alunos com Altas Capacidades (Madrid) entre outros. Assim, como a política educacional brasileira, também está prevista na política espanhola as modalidades de aceleração e enriquecimento curricular para a atenção desse alunado. Nesse sentindo, essa temática requer um número maior de pesquisas que tenham como objetivo estudar os impactos e a eficácia desses atendimentos no desenvolvimento do estudante, visto que até o momento não há produções que investiguem a eficácia destas modalidades a longo prazo.

$\mathrm{Na}$ categoria Avaliação foram alocadas oito teses, em relação aos instrumentos que devem ser utilizados no processo de avaliação dos estudantes AH/SD, como foi discutido anteriormente, não há um consenso para a realização da avaliação, sendo que o referencial teórico adotado irá definir quais serão os instrumentos utilizados. Reys e Chapela (2010) apontam que na avaliação são necessárias medidas objetivas e subjetivas. Mediadas objetivas são aquelas que utilizam instrumentos com grande rigor 
técnico e são padronizados, enquanto as medidas subjetivas são entendidas como aquelas que embora não tenham rigor técnico, abarcam informações importantes provenientes dos familiares, professores, amigos etc. Com base nestes apontamentos, acreditamos que a identificação e avaliação dos estudantes com AH/SD deve-se dar de maneira multimodal, utilizando diferentes instrumentos e informantes, a fim de reunir o maior número de informações possíveis sobre o desenvolvimento e desempenho do mesmo.

Destacamos a categoria Formação Docente, que conta com duas publicações em cada país, como uma importante área a ser pesquisada, visto que o professor deve estar capacitado para conhecer as principais características da $\mathrm{AH} / \mathrm{SD}$, a fim de fazer a identificação inicial e uma avaliação exploratória sobre o desenvolvimento acadêmico destes estudantes.

A temática sobre Família, que aparece somente no levantamento espanhol, também deve ser destacada, visto que os membros da família são os primeiros que identificam o desenvolvimento precoce de seus filhos (SABATELLA, 2012), além de acompanharem o cotidiano da criança, possibilitar o acompanhamento e o acesso a programas e recursos de atenção.

Outra categoria temática que encontramos nas publicações espanholas foi Gênero. Estudos revelam que a maioria dos estudantes com AH/SD identificados são do sexo masculino (MAIA-PINTO; FLEITH, 2004; WINNER, 1998). O “Informe 2014 sobre el Estado del Sistema Educativo” (ESPANHA, 2014) também corrobora com esses dados, ao revelar que na Espanha 66,4\% das pessoas identificadas como AH/SD são do sexo masculino. Segundo Howell, Heward e Swassing (1998), os estereótipos sobre os papeis sexuais, as barreiras sociais, os conflitos entre educação, matrimônio e família tem sido obstáculos para a identificação e desenvolvimento de estudantes do sexo feminino com AH/SD.

Por fim, destacamos a categoria Tecnologias da Informação e Comunicação (TIC), embora somente uma tese tenha sido classificada nessa temática, acreditamos que as tecnologias digitais estão cada vez mais presentes na vida dos estudantes e devem ser cada vez mais utilizadas nos cotidianos escolares, com o objetivo de inovar e enriquecer a prática pedagógica (HOWELL; HEWARD; SWASSING, 1998). A utilização de tais tecnologias favorece a maximização do potencial destes estudantes, como também proporciona o desenvolvimento das competências digitais. 
Em relação ao ano de publicação das teses encontramos produções brasileiras de 1989 a 2013, sendo perceptível um aumento gradativo a partir do ano de 2005 (Figura 3), é importante salientar que atualmente há muitos pesquisadores vinculados a programas de pós-graduação dedicados a esse tema (Soraia Napoleão Freitas, Miguel Claudio Moriel Chacon, Cristina Delou, Denise de Souza Fleith, entre outros), dessa maneira, espera-se que o número de teses sobre a temática aumente nos próximos anos.

Figura 3- Distribuição de teses por ano de publicação - Brasil

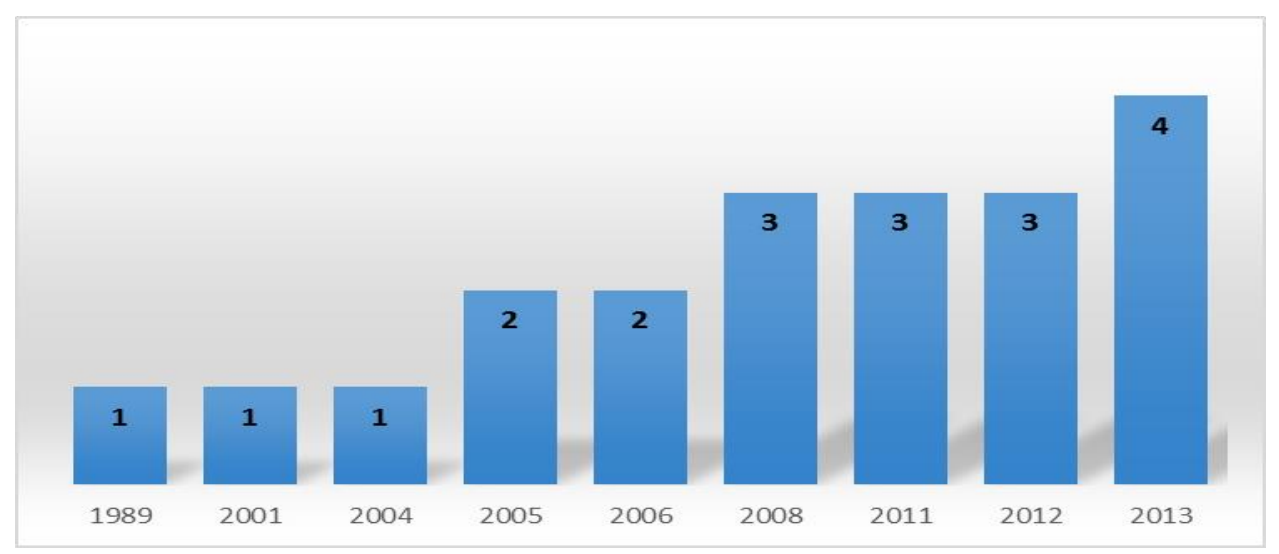

Fonte: Elaboração própria.

Para Freitas (2014, p.132) o crescente aumento no número de pesquisas aumentará “[...] a possibilidade de diversificação de abordagens metodológicas que permitam analisar e dar contribuições importantes para dar conta da temática das Altas Habilidades/Superdotação no Brasil”.

A Figura 4 apresenta a distribuição de teses espanholas por ano de publicação.

Figura 4- Distribuição de teses por ano de publicação - Espanha

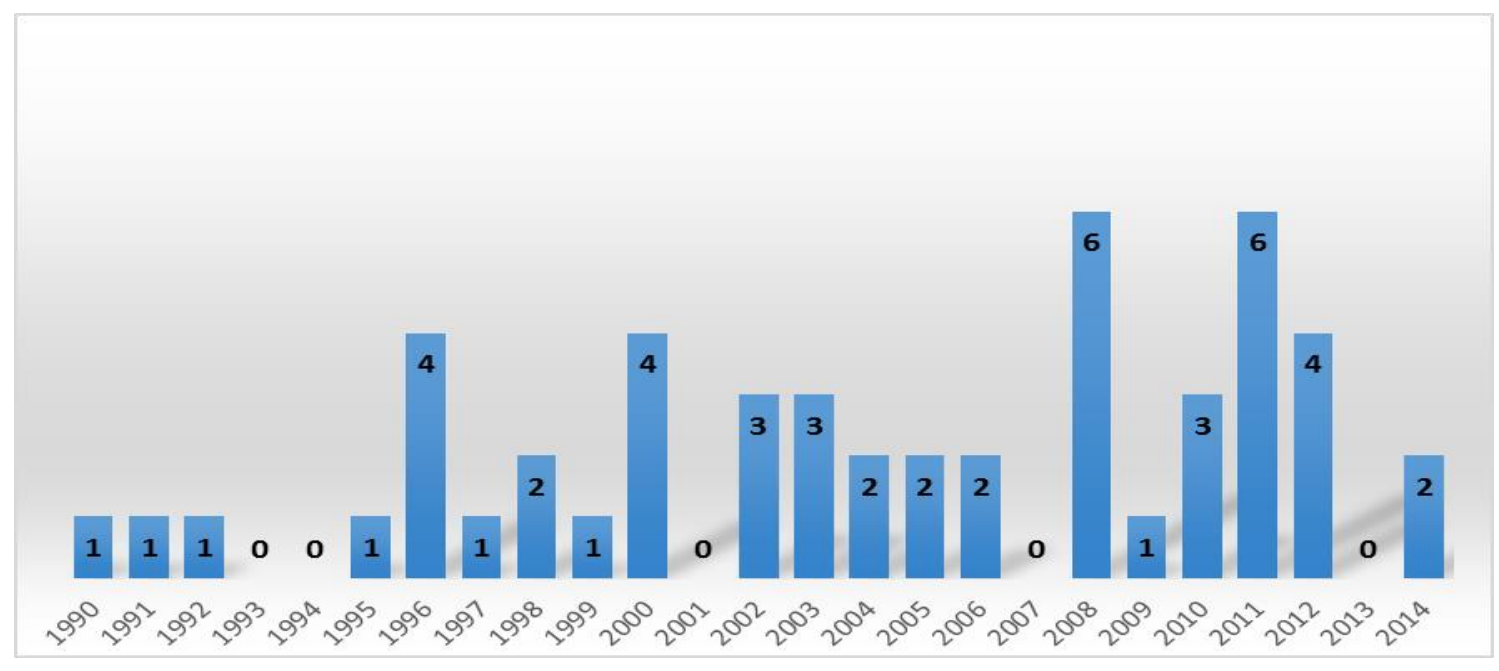

Fonte: Elaboração própria. 
O intervalo temporal das publicações espanholas compreende os períodos de 1990 a 2014, embora em alguns anos não tenha sido encontrada nenhuma publicação. O maior número de teses defendidas encontra-se nos anos de 2008 e 2011.

A Lei Orgânica para melhora da qualidade educativa (ESPANHA, 2013), preconiza em seu texto que todos os estudantes possuem talentos e que os sistemas educativos devem contar com instrumentos e estratégias necessárias para reconhecê-los e potencializá-los, diante dessa nova legislação espera-se que um maior número de pesquisadores focalize seu olhar para esses alunos, consequentemente espera-se um aumento gradativo de publicações nessa área para os próximos anos.

A Figura 5 e 6 apresentam a distribuição de teses nas universidades brasileiras e espanholas.

Figura 5 - Distribuição das teses nas universidades brasileiras.

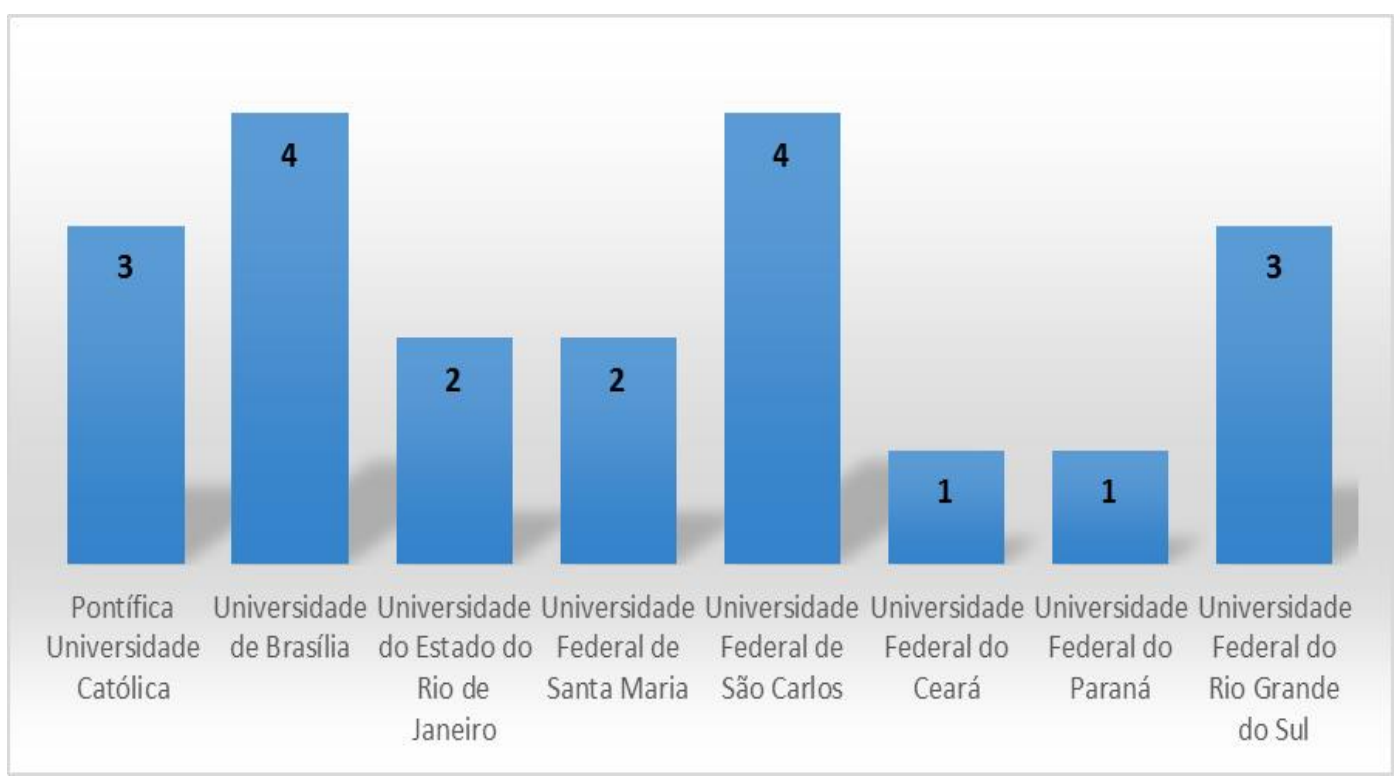

Fonte: Elaboração própria

Observando o número de teses defendidas por universidade no Brasil, percebemos que há uma maior concentração de teses nas universidades federais, representando $75 \%$, enquanto que as universidades particulares contam com $15 \%$ e as estaduais com $10 \%$ do total de produções. 
Figura 6 - Distribuição das teses nas universidades espanholas

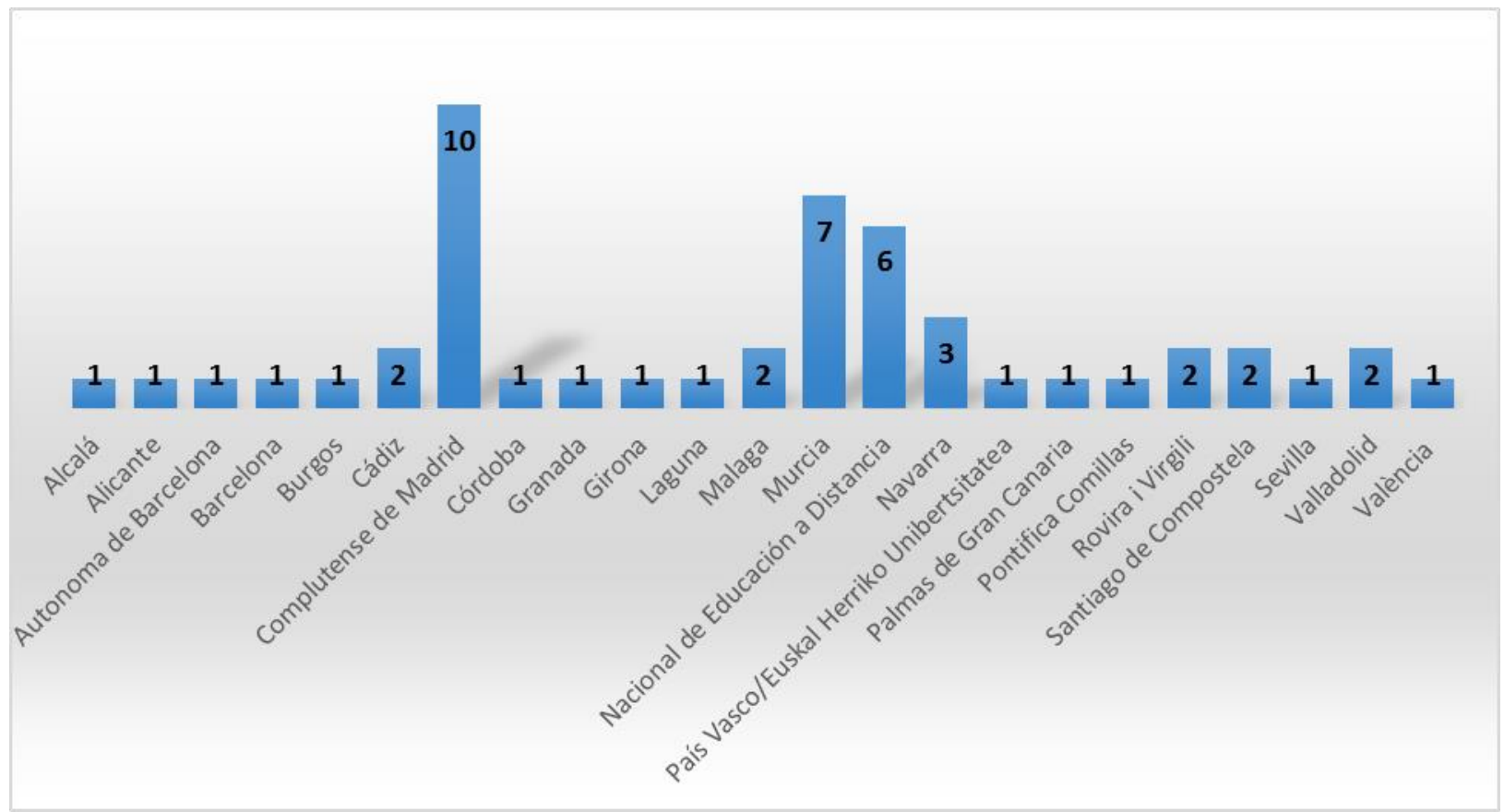

Fonte: Elaboração própria.

Observando a distribuição das teses espanholas por universidade (Figura 6), percebemos que $94 \%$ do total de produções são de universidades públicas e $6 \%$ referentes a universidades particulares (Universidade Pontífica Comillas e Universidade Rovira e Virgili). A Universidade Complutense de Madrid destaca-se com 20\% do total de publicações, sendo esta uma das universidades mas prestigiada da Espanha e com forte tradição na formação de professores e ensino para a diversidade.

\section{Considerações finais}

O panorama brasileiro e espanhol em relação as teses de doutorado na área da AH/SD revela por meio de 70 produções, que as temáticas predominantes estão relacionadas aos temas: identificação, avaliação, identidade e atendimento. Em relação ao ano de publicação das teses encontradas nos dois levantamentos realizados, os anos de 2008 e 2011 são os que destacam-se com nove teses defendidas em cada ano. Sobre o local de publicação, as universidades públicas de ambos os países contam com o maior número de teses defendidas na área.

Diante do exposto, percebemos que embora o número de publicações tenha aumentado progressivamente, esse ainda figura-se como incipiente frente ao número de publicações de outras áreas e a demanda de trabalho que esses estudantes requerem. 
Estudar a área das AH/SD é identificar e dar voz a um alunado, que embora tenha um potencial cognitivo superior, também apresenta necessidades educativas específicas, e tem o direito garantido em lei de serem identificados, avaliados e atendidos.

Além de ser uma reserva social, atender esses estudantes significa também orientar o uso desse potencial cognitivo a um bem comum, pesquisas evidenciam (SOUZA, 2005) que muitos estudantes que tem seu potencial ignorado, podem ter inclinações para a criminalidade, visto que muitas vezes são incompreendidos e não se sentem incluídos dentro da sociedade.

Maximizar o potencial desse alunado, além de contemplar os princípios de uma educação equitativa, podem trazer inúmeros benefícios para a sociedade, uma vez que esses estudantes podem ser os grandes desencadeadores do desenvolvimento cultural, social e tecnológico de seus países.

\title{
BRAZILIAN AND SPANISH PANORAMA ON DOCTORAL DISSERTATIONS IN THE AREA OF HIGH ABILITY / GIFTEDNESS
}

\begin{abstract}
In Brazil the area of High Ability/Giftedness was initialy contemplated in LDB 5692/71 (BRASIL, 1971), while in Spain the starting point occurs on the Real Decreto 696/1995 (ESPANHA, 1995), ensuring to the student body the right of identification and care. Aiming to contribute with the researches in this area, we elaborated the actual brazilian and Spanish panorama regarding the doctoral theses about HA/G. To perform this investigation we consulted the Brazilian Digital Library of Theses and Dissertations and the Database of Doctoral Theses. There were found a total of 70 theses, wherein 20 brasilian and 50 spanish. Based on the analysis of the title, the abstract and the keywords, we listed thematic categories, wherein predominant: Identity, Identification, Evaluation. The first brazilian theses defended date 1989, while in Spain the first theses date 1990. Regargind the publishing place, in Brazil we realize there is a predominance over federal universities, while in Spain, the Universidade Comlutense de Madrid excels in the number of publications. We realize that although the number of publications has grown steadily, this figure is still incipiente in comparison with the number of publications of other áreas and the labor demand that these studants require.
\end{abstract}

KEY WORDS: High abilities/giftedness. Literature review. Brazil. Spain.

\section{REFERÊNCIAS}

ALONSO, J. A. Y BENITO, Y. Superdotados: adaptación escolar y social en Secundaria. Madrid: Narcea, 1996. 
BRASIL. Lei n.5.692, de 11 de agosto de 1971. Fixa diretrizes e bases para o ensino de $1^{\circ}$ e $2^{\circ}$ graus, e dá outras providências. Diário Oficial [da] República Federativa do Brasil, Brasília, DF, 12 ago. 1971.

Lei n.9.394, de 20 de dezembro de 1996. Estabelece as diretrizes e bases da educação nacional. Diário Oficial [da] República Federativa do Brasil, Brasília, DF, 23 dez. 1996.

- Ministério da Educação. Política Nacional de educação especial na perspectiva da educação inclusiva. Brasília: MEC/SEEP, 2008.

CHACON, M. C. M.; PEDRO, K. M.; KOGA, F. O. Programa de Atenção ao aluno Precoce com Comportamentos de Altas Habilidades/Superdotação (PAPAHS). La Nouvelle Revue de l'Adaptation et de la Scolarisation, [S.1.], v.65, p.13-29, 2014.

ESPANHA. Informe 2014 sobre el estado del sistema educativo. Madrid: Ministerio de Educación, Cultura y Deporte, 2014. Disponível em: <http://www.mecd.gob.es/cee/publicaciones/informes-del-sistema-educativo/informe2014.html . Acesso em: 10 abr. 2015.

$\overline{\text { Madrid }}$. Ley Orgánica 2/2006 de Educación (LOE). Boletín Oficial del Estado, Madrid, N.106, 2006. <http://www.boe.es/boe/dias/2006/05/04/pdfs/A17158172017.pdf>. Acesso em: 10 abr. 2015.

Ley Orgánica de Educación 2013 (LOE). Boletín Oficial del Estado, Madrid, n.295, 2013. Disponível em: <http://www.boe.es/boe/dias/2013/12/10/pdfs/BOE-A2013-12886.pdf $\geq$. Acesso em: 11 abr. 2015.

Real Decreto 696/1995. Boletín Oficial del Estado, Madrid, n.131, 1995. Disponível em: <https://www.boe.es/buscar/doc.php?id=BOE-A-1995-13290>. Acesso em: 10 abr. 2015.

Real Decreto 943/2003. Boletín Oficial del Estado, Madrid, n.182, 2003. Disponível em: <http://www.boe.es/boe/dias/2003/07/31/pdfs/A29781-29783.pdf>. Acesso em: 10 abr. 2015.

FREITAS, S. N. Altas Habilidades/Superdotação em pesquisa: um olhar dirigido. In: OMOTE, S.; OLIVEIRA, A. A. S.; CHACON, M. C. M. Ciência e conhecimento em educação especial. São Carlos: Marquezine \& Manzini: ABPEE, 2014. p.125-134.

; PEREZ, S. G. P. B. Altas Habilidades/Superdotação: atendimento especializado. 2.ed. Marília: ABPEE, 2012.

GARCÍA-RON, A.; VÁZQUEZ, J. S. Niños con altas capacidades intelectuales. Signos de alarma, perfil neuropsicológico y sus dificultades académicas. Anales de Pediatría Continuada, [S.1.], v.9, n.1 p.69-72, 2011.

HOWELL, R. D.; HEWARD, W. L.; SWASSING, R. H. Los alumnos superdotados. In: HEWARD, W. L. Niños excepcionales: una introducción a la educación especial. Madrid: Pearson Educación, 1998. p.435-480. 
MAIA-PINTO, R. R.; FLEITH, D. S. Avaliação das práticas educacionais de um programa de atendimento a alunos superdotados e talentosos. Psicologia Escolar e Educacional, Campinas, v.8, n.1, p.55-66, jun. 2004.

OMOTE, S. Produção acadêmica em educação especial. In: OMOTE, S.; OLIVEIRA, A. A. S.; CHACON, M. C. M. Ciência e conhecimento em educação especial. São Carlos: Marquezine \& Manzini: ABPEE, 2014. p.13-24.

PALUDO, K. I.; LOOS-SANT'ANA, H.; SANT'ANA-LOOS, R. S. A identidade da pessoa com Altas Habilidades/Superdotação sob a ótica do sistema teórico da afetividade ampliada. Revista Eletrônica do curso de Psicologia da Faculdade Dom Bosco, Curitiba, n.12, p.1-17, 2013.

RENZULLI, J. S. What makes giftedness?: eeexamining a definition. Phi Delta Kappan, [S.1.], v.60, n.3, p.180-184, 1978.

REYES, M. T. F.; CHAPELA, M. T. S. Cómo detector y evaluar a los alumnus con altas capacidades intelectuales. Sevilla: Díada Editora, 2010.

SABATELLA, M. L. P. Expandir horizontes para compreender alunos superdotados. In: MOREIRA, L. C.; STOLTZ, T. (Org). Altas Habilidades/Superdotação, talento, dotação e educação. Curitiba: Juruá, 2012. p.113-128.

SANZ, C. Entrevista: ser superdotado en Andalucía y no en Cataluña. Madrid: El País, $2015 . \quad$ Disponível em: <http://politica.elpais.com/politica/2015/03/31/actualidad/1427824793_300481.html_. Acesso em: 01 abr. 2015.

SILVA, R. C. A falsa dicotomia qualitativo-quantitativo: paradigmas que informam nossas práticas de pesquisas. In: ROMANELLI, G.; BIASOLI-ALVES, Z. M. M. (Org.). Diálogos metodológicos sobre prática de pesquisa. Ribeirão Preto: Legis Summa, 1998. p.159-174.

SMITH, D. D. Introdução a educação especial: ensinar em tempos de inclusão. Porto Alegre: ARTMED, 2008.

SOUZA, M. L. L. Indicadores de Altas Habilidades entre os reclusos do Centro de Atendimento sócio-educativo no município de Santo Ângelo - RS. Santa Maria: UFSM, 2005. Disponível em: <http://cascavel.cpd.ufsm.br/tede>. Acesso em: 15 nov. 2014.

WINNER, E. Crianças superdotadas: mitos e realidades. Porto Alegre: Artes Médicas, 1998. 